\title{
Remdesivir use in pregnant women with severe COVID-19
}

\section{Sarada Mamilla ${ }^{1 *}$, Harikishan Boorugu ${ }^{2}$, Ramya Bharghavi B. P. L. ${ }^{1}$, Bhavana Priya Kodam ${ }^{1}$, Sandhya Rani Adapa ${ }^{1}$, Gayathri Kamani' ${ }^{1}$, Tejaswi Vuta ${ }^{1}$}

\begin{abstract}
${ }^{1}$ Department of Obstetrics and Gynecology, ${ }^{2}$ Department of Internal Medicine, Yashodha Hospital, Hyderabad, Telangana, India
\end{abstract}

Received: 05 August 2021

Accepted: 08 October 2021

\author{
*Correspondence: \\ Dr. Sarada Mamilla, \\ E-mail: mamillasarada@yahoo.co.in
}

Copyright: () the author(s), publisher and licensee Medip Academy. This is an open-access article distributed under the terms of the Creative Commons Attribution Non-Commercial License, which permits unrestricted non-commercial use, distribution, and reproduction in any medium, provided the original work is properly cited.

\begin{abstract}
Numerous therapeutic strategies are proposed and tested for SARS CO-V2 infection. Remdesivir is researched and proposed by various societies. Studies about efficacy and safety in pregnancy are limited. A case series of 22 pregnant women effected with severe COVID disease and who received remdesivir, over a period of 1 year from May 2020 to May 2021 is presented. The 12 antenatal and 10 post-partum women were included. Demographic factors, baseline, day 3 and day 7 blood values of haemoglobin, total leukocyte count, platelets, liver enzymes, serum creatinine and D-dimers were collected. Adverse events were reported. Pregnancy complications and foetal and neonatal complications were studied. Pre-eclampsia was the most common comorbidity. The $99 \%$ of pregnant women and $100 \%$ of postpartum women recovered from COVID disease after remdesivir use. Lab investigations did not change considerably during the week of remdesivir use, suggesting its safety. Incidence of adverse events reported is $36.3 \%$, of these $9 \%$ are serious adverse events. There are no antenatal or post-natal complications. No incidence of teratogenicity, foetal or neonatal complications. Incidence of feto-maternal transmission was 9\%. Remdesivir is effective in treating severe SARS-CoV2 infection and has safety profile in pregnancy with regard to maternal and foetal effects.
\end{abstract}

Keywords: Remdesivir in pregnancy, Fetal effects of remdesivir, Neonatal side effects of remdesivir, Maternal safety with remdesivir

\section{INTRODUCTION}

Corona disease caused by novel corona virus, has caused many deaths worldwide and such sudden increase in infections seem to be occurring throughout the world. Clinical trials have investigated a number of pharmacological treatment strategies in nonpregnant populations, and other pharmacologic treatment strategies are ongoing. Remdesivir is an intravenous nucleotide prodrug of an adenosine analogue. Inside the cell, pro-drug remdesivir is converted into nucleoside monophosphate or nucleotide analogue which goes into further phosphorylation events yielding active nucleoside form triphosphate analogue. The triphosphate analogue is utilized by viral RNA dependant RNA polymerase (RdRp), such utilization inhibits viral replication.
Remdesivir is antiviral drug which was approved by FDA in October 2020 for treatment of COVID disease. Remdesivir improves clinical outcomes of hospitalized patients with COVID-19 and a 5-day regimen, instead of a 10-day regimen, may be sufficient for treatment. Moreover, remdesivir appears as tolerable as other comparators or placebo. ${ }^{1}$ The living guideline of WHO states that, remdesivir does improve patient-important outcomes (limited evidence). ${ }^{2}$

pregnant women are susceptible to SARS-COV2 infection as nonpregnant women. Pregnant women are excluded from clinical trials, because of concerns regarding foetal safety. ${ }^{3}$ SMFM (Society for maternal, foetal medicine) recommends that remdesivir be offered to pregnant patients with COVID-19, meeting criteria for 
compassionate use. ${ }^{4}$ RCOG (Royal college of obstetricians and gynaecologists) states that remdesivir should be used only if clinicians believe the benefits of treatment outweigh the risks to the individual. ${ }^{5}$ FOGSI (Federation of obstetricians and gynaecologists of India) also recommends that remdesivir should not be withheld from pregnant patient if otherwise indicated. ${ }^{6}$ GOI has issued advisory on remdesivir use stating that-remdesivir is to be used only in select moderate/severe hospitalised COVID19 patients on supplemental oxygen as it is a reserve drug approved under emergency use authorization only based on limited scientific evidence globally. ${ }^{7}$ Literature about the safety of remdesivir in pregnancy is very limited. We did a single centre study of remdesivir use in pregnancy, to study its efficacy and safety in pregnant women.

\section{CASE SERIES}

Pregnant women who were admitted with COVID and met criteria to use remdesivir were included in the study. Pregnant women with COVID who did not receive remdesivir were excluded. Criteria to start remdesivir were-hospitalized patients with severe COVID-19 (defined as $\mathrm{SpO}_{2} \leq 94 \%$ on room air/requiring supplemental oxygen, or requiring mechanical ventilation, or requiring ECMO.) A total of 5 doses of remdesivir was given, with a loading dose of $200 \mathrm{mg}$ on day 1, followed by 100 $\mathrm{mg} /$ day for remaining 4 days. Written informed consent was taken from all pregnant and postpartum women who received remdesivir and for inclusion in study. Demographic factors, comorbidities, baseline $\mathrm{O}_{2}$ support and $\mathrm{O}_{2}$ support at time of discharge were studied. Baseline blood investigations like haemoglobin, platelet count, total leukocyte count, liver transaminases, renal function tests were also studied. Antenatal adverse events, foetal risks and postnatal adverse events were also included in study. Corticosteroids and cephalosporin group of antibiotics were the concurrent medication used during hospital stay.

All data were analysed using IBM SPSS V20.0 software.

A total of 22 pregnant and just delivered pregnant women were included in study, 12 antepartum and 10 postpartum women. (Median post-partum day 3, range from 0-7). Median age group was 29 in both the groups, range 22-35. Pre-eclampsia (18.2\%) was the most common comorbidity followed by gestational diabetes (13.2\%) $72 \%$ (16) of women were overweight and $28 \%$ (6) were of normal BMI. Demographic factors are illustrated in Table 1.

The $99 \%$ of pregnant women and $100 \%$ of postpartum women recovered from COVID disease after remdesivir use. There was 1 maternal death due to COVID. Mean number of admission days was 9.5 days (4-28 days). Seven $(58 \%)$ of antenatal women needed ventilation and Emergency delivery was done in 5 women to improve maternal outcomes and lack of evidence about safety of remdesivir use in pregnancy. One woman continued pregnancy after extubating and there was one maternal death after 20 days on ventilator. Mean number of days of ventilation was 3 days (1-4 days).

Table 1: Demographic factors.

\begin{tabular}{|c|c|c|}
\hline Characteristics & $\begin{array}{l}\text { Antenatal } \\
(\%)\end{array}$ & $\begin{array}{l}\text { Postnatal } \\
(\%)\end{array}$ \\
\hline \multicolumn{3}{|l|}{ Age (Years) } \\
\hline$<30$ & $7(58.3)$ & $3(30)$ \\
\hline$>30$ & $5(41.7)$ & $7(70)$ \\
\hline \multicolumn{3}{|l|}{ Parity } \\
\hline Primi & $7(31.8)$ & -- \\
\hline Multi & $5(22.7)$ & -- \\
\hline Postpartum & -- & $10(45.4)$ \\
\hline \multicolumn{3}{|l|}{ BMI $\left(\mathrm{kg} / \mathrm{m}^{2}\right)$} \\
\hline $18-24.9$ & $5(41.6)$ & $6(60)$ \\
\hline $25-30$ & $6(50)$ & $4(40)$ \\
\hline$>30$ & $1(8.3)$ & -- \\
\hline \multicolumn{3}{|l|}{ Co-morbidities } \\
\hline Obesity & $1(8.3)$ & -- \\
\hline Gestational diabetes & $2(16.7)$ & $1(10)$ \\
\hline Pre-eclampsia & $2(16.7)$ & $2(20)$ \\
\hline No comorbidities & $7(58.3)$ & $7(70)$ \\
\hline \multicolumn{3}{|l|}{$\mathrm{O}_{2}$ support baseline } \\
\hline \multicolumn{3}{|l|}{ Invasive } \\
\hline Ventilator & $1(8.3)$ & -- \\
\hline \multicolumn{3}{|l|}{ Non-invasive } \\
\hline NIV & $1(8.3)$ & $1(10)$ \\
\hline HIFNO & $1(8.3)$ & $4(40)$ \\
\hline LFNO & $3(25)$ & $1(10)$ \\
\hline Room air & $6(50)$ & $4(40)$ \\
\hline
\end{tabular}

Baseline blood investigations which included haemoglobin, TLC, platelets, D-dimer, serum creatinine, serum bilirubin, liver transaminases were done on day 1,3 and 6 (Table 2). Values did not change considerably with remdesivir use, suggesting safety of its use.

Incidence of adverse events reported is $36.3 \%$ (Table 3 ). Of these serious adverse events is $9 \%$. Preterm delivery was done in 5 patients to improve maternal outcome. Steroid induced hyperglycaemia, fungal sinusitis, peripartum cardiomyopathy were seen as pregnancy complications, mostly due to COVID disease and concurrent steroid use. One maternal death was seen due to severe COVID disease.

We had 11 deliveries in study group, all were caesarean deliveries. Of these $9 \%$ were done in extremely preterm group (26-28 weeks), $28 \%$ were done in 28-32 weeks. gestational period and $63 \%$ were done in women more than 32 weeks. Reason for emergency caesarean delivery was, to facilitate remdesivir use (5), previous caesarean delivery (3), multiple pregnancy (1), PROM (1), breech (1). Of 10, women who continued pregnancy after taking remdesivir, 1 had induced miscarriage at 22 weeks due to fungal sinusitis, 2 had normal vaginal deliveries at term, and rest are still continuing pregnancy at time of writing this article. 
Table 2: Biochemical variables.

\begin{tabular}{|llllll|}
\hline Variables & N & Mean & SD & Q1 & Q3 \\
\hline Hb, day 1 & 22 & 11.14 & 1.58 & 10.00 & 12.00 \\
\hline Hb, day 3 & 21 & 10.67 & 1.43 & 10.00 & 12.00 \\
\hline Hb, day 6 & 21 & 10.57 & 1.29 & 9.50 & 11.50 \\
\hline TLC, day 1 & 22 & 10103.14 & 5315.60 & 6335.00 & 12722.50 \\
\hline TLC, day 3 & 22 & 13379.41 & 5132.59 & 8780.00 & 18531.75 \\
\hline TLC, day 6 & 22 & 12528.41 & 3957.27 & 9951.00 & 14455.00 \\
\hline Platelets, day 1 & 22 & 2.23 & 0.61 & 2.00 & 2.25 \\
\hline Platelets, day 3 & 22 & 2.82 & 0.73 & 2.00 & 3.00 \\
\hline Platelets, day 6 & 22 & 3.09 & 0.92 & 2.00 & 4.00 \\
\hline S. creatinine, day 1 & 22 & 0.32 & 0.48 & 0.00 & 1.00 \\
\hline S. creatinine, day 3 & 22 & 0.32 & 0.48 & 0.00 & 1.00 \\
\hline S. creatinine, day 6 & 22 & 0.41 & 0.50 & 0.00 & 1.00 \\
\hline D dimer, day 1 & 22 & 1256.77 & 892.03 & 586.25 & 1507.75 \\
\hline D dimer, day 3 & 22 & 1329.14 & 1326.23 & 682.75 & 1503.00 \\
\hline D dimer, day 6 & 22 & 1262.09 & 1079.72 & 681.00 & 1258.25 \\
\hline AST, day 1 & 22 & 67.14 & 75.79 & 31.75 & 79.75 \\
\hline AST, day 3 & 22 & 55.36 & 34.91 & 34.00 & 65.50 \\
\hline AST, day 6 & 22 & 49.77 & 21.40 & 33.75 & 59.75 \\
\hline ALT, day 1 & 21 & 59.14 & 57.53 & 23.00 & 51.00 \\
\hline ALT, day 3 & 21 & 52.67 & 43.17 & 26.50 & 53.50 \\
\hline ALT, day 6 & 21 & 49.14 & 39.02 & 25.00 & 50.00 \\
\hline S. bilirubin, day 1 & 22 & 0.45 & 0.51 & 0.00 & 1.00 \\
\hline S. bilirubin, day 3 & 22 & 0.50 & 0.51 & 0.00 & 1.00 \\
\hline S. bilirubin, day 6 & 22 & 0.36 & 0.49 & 0.00 & 1.00 \\
\hline
\end{tabular}

NICU admissions were done in 6 patients and all were admitted because of preterm. Feto-maternal transmission of COVID disease was observed in 2 women. No teratogenicity was observed in all 12 patients who received remdesivir in pregnancy. Eight patients received remdesivir in II trimester and 4 patients in III trimester. There were no neonatal deaths.

Table 3: Adverse events.

\begin{tabular}{|lll|}
\hline Adverse event & Antenatal & Post-natal \\
\hline Mild & & \\
\hline Maternal tachycardia & 1 & -- \\
\hline Maternal bradycardia & 1 & -- \\
\hline Rectal tenesmus & -- & 1 \\
\hline Hyper glycemia & 1 & -- \\
\hline Rectus sheet haematoma & -- & 1 \\
\hline Severe & & \\
\hline $\begin{array}{l}\text { Peripartum } \\
\text { cardiomyopathy }\end{array}$ & -- & 1 \\
\hline Fungal sinusitis & -- & 1 \\
\hline Maternal death & 1 & \\
\hline
\end{tabular}

\section{DISCUSSION}

There are few studies reported in literature about remdesivir use in pregnancy. Study done by Burwick et al reported 86 pregnant women who had severe COVID and received remdesivir. ${ }^{8}$ There are isolated case reports of remdesivir use in pregnancy. ${ }^{9-13}$ All studies have reported effectiveness of remdesivir in treating COVID disease. Our study was done with primary aim to study the effectiveness, maternal and foetal safety with remdesivir use. A phase I prospective, open label, non-randomized opportunistic study to evaluate the PK and safety of RDV when administered to pregnant and non-pregnant women of childbearing potential for treatment of COVID-19 in a cohort of 40, with 20 in each arm is planned by national institute of allergy and infectious diseases (NIAID), US. Study will complete in April 2022. Human data for the use of this agent in pregnant women with COVID-19 are extremely limited. Mulunga et al did a study of remdesivir in the treatment of Ebola virus disease, six pregnant women were assigned to receive remdesivir and there were no significant foetal/ new-born, pregnancy, or maternal adverse events reported in any of the members of this subgroup. ${ }^{14}$ In the case series reported by McCoy et al, 1 patient had to discontinue remdesivir due to worsening transaminitis. ${ }^{9}$ In our study we did not find any rise in Liver enzymes. Incidence of serious adverse events was $16 \%$ in study done by Burwick et al while we report an incidence of serious adverse events as $9 \%$. Remdesivir was well tolerated in pregnancy with the good neonatal outcomes.

Limitations of this study are, study sample is very small and no comparative cohort available. Non pregnant women of similar demographic factors should be included for proper comparison. 


\section{CONCLUSION}

Lot of research has been done to understand pathophysiology and clinical manifestations of SARS COv2 disease. It has moved from a primary lung disease to a thrombo-inflammatory disease, which can affect any organ, New therapeutic modalities are being suggested. Remdesivir is an effective drug, especially in pregnancy with its promising safety.

\section{Funding: No funding sources}

Conflict of interest: None declared

Ethical approval: Not required

\section{REFERENCES}

1. Lai CC, Chen CH, Wang CY, Chen KH, Wang YH, Hsueh PR. Clinical efficacy and safety of remdesivir in patients with COVID-19: a systematic review and network meta-analysis of randomized controlled trials. J Antimicrob Chemother. 2021;dkab093.

2. Siemieniuk R, Rochwerg B, Agoritsas T, Lamontagne $\mathrm{F}$, Leo YS, Macdonald $\mathrm{H}$ et al. A living WHO guideline on drugs for COVID-19. Bri Med J. 2020;370:m3379.

3. Taylor MM, Kobeissi L, Kim C. Inclusion of pregnant women in COVID-19 treatment trials: a review and global call to action. Lancet Glob Heal. 2020;9(3):e366-71.

4. Society for Maternal-Fetal Medicine. Coronavirus (COVID-19) and Pregnancy: What Maternal Fetal Medicine Subspecialists Need to Know. 2020.

5. Royal College of Obstetricians and Gynaecologists. Coronavirus (COVID-19) infection and pregnancy, 2020. Available

at: https://www.rcog.org.uk/globalassets/documents/gui delines/coronavirus-covid-19-infection-inpregnancy-v3-20-03-18.pdf. Accessed on 10 Jan, 2021.

6. Gandhi A, Ganatra A, Tank P. FOGSI GCPR on Pregnancy with COVID-19 infection Version 2. Federation of Obstetric and Gynaecological Societies of India. 2020. https://www.fogsi.org/fogsi-gcpr-onpregnancy-with-COVID-19-infection-version-2/. Accessed on $25 \mathrm{Jul}, 2020$.

7. Ministry of Health and Family Welfare, Government of India. Advisory for rational use of remdesivir for COVID-19 treatment. 2021.

8. Burwick RM, Yawetz S, Stephenson KE, Collier AR, Sen P, Blackburn BG et al. Compassionate use of remdesivir in pregnant women with severe coronavirus disease 2019. Clin Infect Dis. 2020; ciaa1466.

9. McCoy JA, Short WR, Srinivas SK, Levine LD, Hirshberg A. Compassionate use of remdesivir for treatment of severe coronavirus disease 2019 in pregnant women at a United States academic center. Am J Obstet Gynecol MFM. 2020;2(3):100164.

10. Igbinosa I, Miller S, Bianco K. Use of remdesivir for pregnant patients with severe novel coronavirus disease 2019. Am J Obstet Gynecol. 2020;223:76870 .

11. Maldarelli GA, Savage M, Mazur S, Oxford-Horrey C, Salvatore M, Marks KM. Remdesivir treatment for severe COVID-19 in third- trimester pregnancy: case report and management discussion. Open Forum Infect Dis. 2020;7.

12. Jacobson J, Antony K, Beninati M, Alward W, Hoppe KK. Use of dexamethasone, remdesivir, convalescent plasma and prone positioning in the treatment of severe COVID-19 infection in pregnancy: $\mathrm{z}$ case report. Case Reports Women's Heal. 2021;29.

13. Naqvi M, Zakowski P, Glucksman L, Smithson S, Burwick RM. Tocilizumab and remdesivir in a pregnant patient with coronavirus disease 2019 (COVID-19). Obstet Gynecol. 2020;136:1025-9.

14. Mulangu S, Dodd LE, Davey RT, et al. A randomized, controlled trial of ebola virus disease therapeutics. N Engl J Med. 2019;381:2293-303.

Cite this article as: Mamilla $\mathrm{S}$, Boorugu $\mathrm{H}$, Bharghavi BPLR, Kodam BP, Adapa SR, Kamani G et al. Remdesivir use in pregnant women with severe COVID-19. Int J Reprod Contracept Obstet Gynecol 2021;10:4311-4. 